\title{
Article \\ Learning transportation sustainability through Human Powered Vehicle design - A ten-year experience at Politecnico di Torino
}

\author{
Paolo Baldissera ${ }^{1, t, \ddagger(1)}$ and Cristiana Delprete ${ }^{1, \ddagger}$ \\ 1 Politecnico di Torino; paolo.baldissera@polito.it; cristiana.delprete@polito.it \\ * Correspondence: paolo.baldissera@polito.it; Tel.: +39-011-090-6917 \\ + Current address: Politecnico di Torino - Corso Duca degli Abruzzi, 24 - 10137 Torino, Italy \\ $\ddagger \quad$ These authors contributed equally to this work.
}

Version October 23, 2018 submitted to

\begin{abstract}
In this work, the decennial experience of Policumbent student team at Politecnico di Torino is summarized by focusing on the acquired knowledge in design of Human Powered Vehicles (HPVs) and on soft skills developed by both students and staff. Policumbent was funded by the authors at the end of 2008 in order to gather engineering students interested in design and construction of HPVs. In the last decade, the team has grown from 10 up to 50 students enrolled per year, exploring a range of HPV design for sports and mobility. Even when focusing on sport vehicles and extreme HPVs for speed record, such kind of projects allows students to familiarize with important concepts related to sustainable mobility: the amount of resistive forces and dissipated power, the role of vehicle weight and the impact of acceleration on the overall energetic balance as far as fundamental concepts about energy consumption, efficiency and emissions of the "human engine" in comparison with other kind of engines. By touching with hands such topics in the framework of a "human-centred" design project, the students have opportunity to develop awareness about the impact of design choices on sustainability of any kind of vehicle for transportation. Also, the paper retraces the team evolution path by focusing on a thorough analysis of what factors contributed to the success of this project.
\end{abstract}

Keywords: Project Based Learning; Human Powered Vehicles; Sustainable transportation design

\section{Introduction}

Project Based Learning (PBL) in university educational path is a widely explored approach "based on the constructivist finding that students gain a deeper understanding about a certain topic when they are asked to build their knowledge working with and using ideas" [1]. The roots of this methodology are ascribed to educator and philosopher John Dewey (1959), arguing that students are prone to make a personal investment on a subject if they are engaged in real, meaningful tasks and problems. This approach to education has been widely applied and analysed in the last decades [2-10] and example of PBL projects can be easily found all around the world. A specific form of PBL involves the integration of an heterogeneous group of students within a team [11-18] which is oriented towards design and building of a product (often a vehicle), in order to attend regional, national or international competitions.

Such kind of experience is specifically suitable for engineering students due to three main reasons:

- to provide a hands-on experience where students can find practical application (and thus deeper understanding) of theoretical concepts taught in traditional lectures;

- to stimulate their curiosity on physical phenomena that needs to be deeply understood by engineers in order to achieve successful design;

- to let students develop soft skills that are of primary importance in real world industry where their career is likely to develop. 
The last point is of particular importance since, in design teams, the capability to communicate effectively within members is a key for success. Every product, even an extremely specialized one aiming at a very specific goal, is always the result of an intelligent compromise among contrasting design factors and compromises can be achieved only through communication between the different sub-section of a design team. Moreover, dealing with deadlines in design, construction and testing for a race, makes the students aware of the importance of planning in advance their activities, and they will learn that whether they succeed or fail.

\section{Background: general management of Student Team PBL at Politecnico di Torino}

Student Team PBL (ST-PBL) in Politecnico di Torino started from SAE Formula team (2005) and then gradually expanded with the creation of a Shell-Eco Marathon team (2007), human-powered vehicle design team Policumbent (late 2008) and many others up to the current number of about 15 stable teams plus other 25-30 occasional ST-PBL activities [19]. At least 7 of the 15 stable teams are focused on design and construction of vehicles, including cars for different purposes, motorcycles, boats, drones, aircraft and bicycles.

Student teams are economically supported by Politecnico di Torino through an internal panel in charge for evaluating project proposals according to defined rules. The panel is headed by the Vice Rector for Education and is composed by a mixed group of faculty, technical and administrative staff plus a student delegate. The panel provides 5-6 calendar deadline for the teams to send a proposal, requiring to explain in detail the scope, the time-line and the provisional cost of the project. Then, a small representative of each applicant team is asked to make a short presentation in front of the commission that will finally approve (or reject) a full or partial budget.

After this process, the team receives funds under management of the Department to which belong the Academic Responsible (a mandatory figure) and the group is required to spend all the budget within the planned time-line (usually 1 year). Before submitting a new financial support request, a detailed final report of the previous project must be presented. For any change in the planned use of the money the team is required to ask approval to the panel by email.

Internal organization of the team and the level of interaction with the Academic Responsible and/or other supervisors is not subject to any specific rule and rely on the students and teacher(s) choice. The activity by the supervisors is in the form of volunteering, totally unrelated to their lecture duties and with no rewards in terms of career. No laboratory or workshop space is formally assigned to the teams by the panel and is up to the hosting Department to eventually provide a space. This is a critical point in the overall management of ST-PBL and the University is currently evaluating a solution for all the teams.

Starting from 2012, the active participation to ST-PBL is recognized with credits in almost all engineering courses of Politecnico di Torino. In particular, students from mechanical, aerospace and automotive engineering can obtain 6 credits in their bachelor and 6 or 12 credits in their master careers, depending on the level of dedication (i.e. 12 credits are typically recognized to the team leader and/or to section managers).

Within this general framework, the short decennial history of Policumbent Team PBL has developed as summarized in the next section.

\section{Foundation and short history of Policumbent Team PBL}

Human Powered Vehicles is the term used to indicate a wide range of machines, including the most popular safety-bicycle as a sub-category. In fact, HPVs can be intended for use on land, water (on surface or submersed) and even for flight purposes, all representing an opportunity to create valuable PBL projects as demonstrated by the existence of a significant number of student challenges and competitions that can be easily found all around the world. However, the experience developed at Politecnico di Torino through Team Policumbent [20], deriving its name from Poli(tecnico) and (Re)cumbent, has been strictly focused on laid back vehicles for land use, up to now. In late 2008, the 

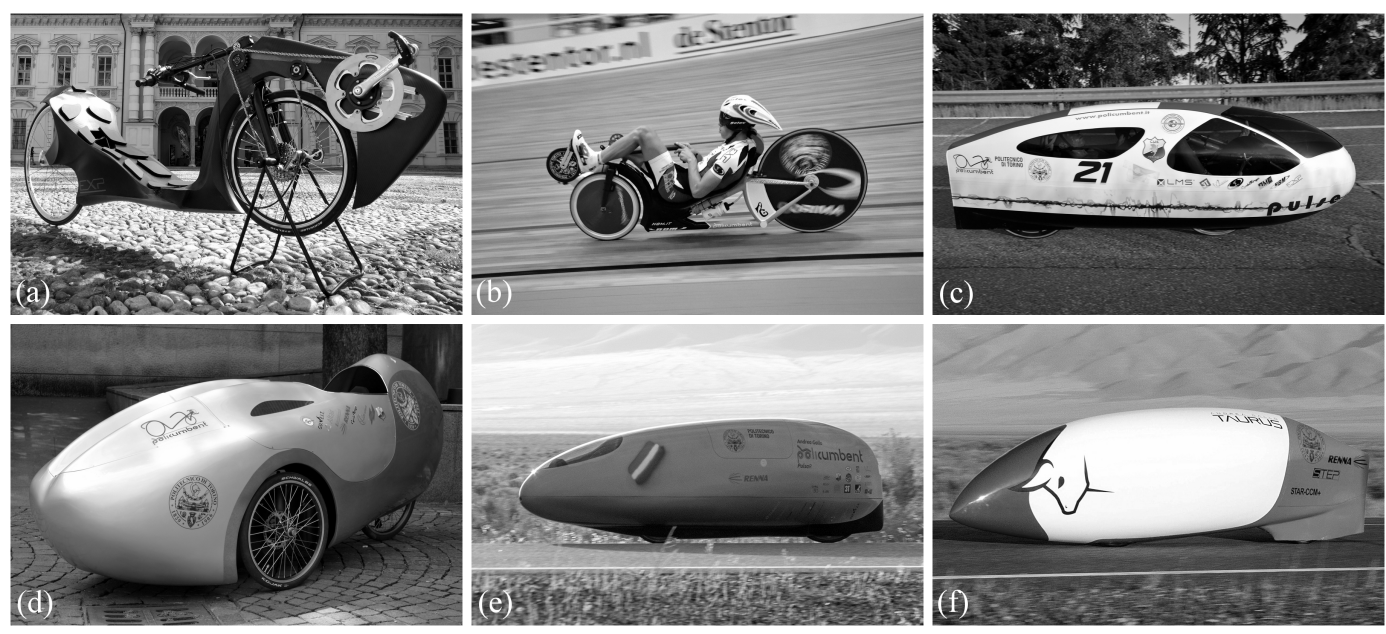

Figure 1. HPV projects realized by the Team: (a) CORA 2010, (b) CorAl-13 2011, (c) Pulse 2012, (d) S-Trike 2014, (e) PulsaR 2015 and (f) Taurus 2017.

authors proposed to a small group of 4 BS and 2 MS students in Mechanical Engineering to work on a HPV project by constituting what is referred now as Team \#1. The Team \#1 enrolled few additional members and received approval for economical support in June 2009 in order to start building its first recumbent bicycle project. The racing debut was held in May 2010 at the WHPVA (World Human Powered Vehicle Association) [21] World Championship in Jersey Island (JE) with no significant results in the competition, but a huge amount of enthusiasm and learning-by-errors experience. Since then, the Team has been annually renewed with new members, but letting "veterans" free to continue their experience, up to the current Team\#10 (academic year 2018/19). This approach allowed to grant a progressive building of the team identity and technical knowledge. New HPV projects were realized in the following years as summarized in Figure 1.

Figure 2 shows the team growth from the foundation up to the current group, including a distinction among new members, veterans (students remaining in team from the previous year) and occasional "Erasmus guest" students that were hosted by the project. The team evolution can be divided in two distinct phases, as summarized in Figure 3:

- $\quad$ phase 1 including two sub-phases:

[1.1] teams \#1 and \#2 (2008-2011): relatively small teams with 11 nominal members with a good active participation rate (around $60 \%$ );

[1.2] teams \#3 to \#5 (2012-2014), slow growing teams up to 17 students, but a lower active participation rate (less than $40 \%$ );

- $\quad$ phase 2 - teams \#6 to \#9 (2015-2018): rapid growth from 20 to 50 nominal members and higher participation rate (around 70\%).

A more detailed overview of the project evolution is summarized in Figure 3, where each team has an attribution title that can be explained as follow:

- foundation and continuation: team \#1 was in fact prolonged over a couple of academic years in order to start from scratch a totally new activity without any background;

- confirmation: recruiting for team \#2 and realizing a 2nd bike project confirmed the intention and the capability to renew and prosecute over years;

- evolution: team \#3 started aiming at ambitious goals and more complex design by switching towards fully faired vehicles;

- pause: team \#4 suffered the pressure to develop two separated projects (sport records and green mobility), resulting in a slowed development process, difficult organization and unclear goals; 


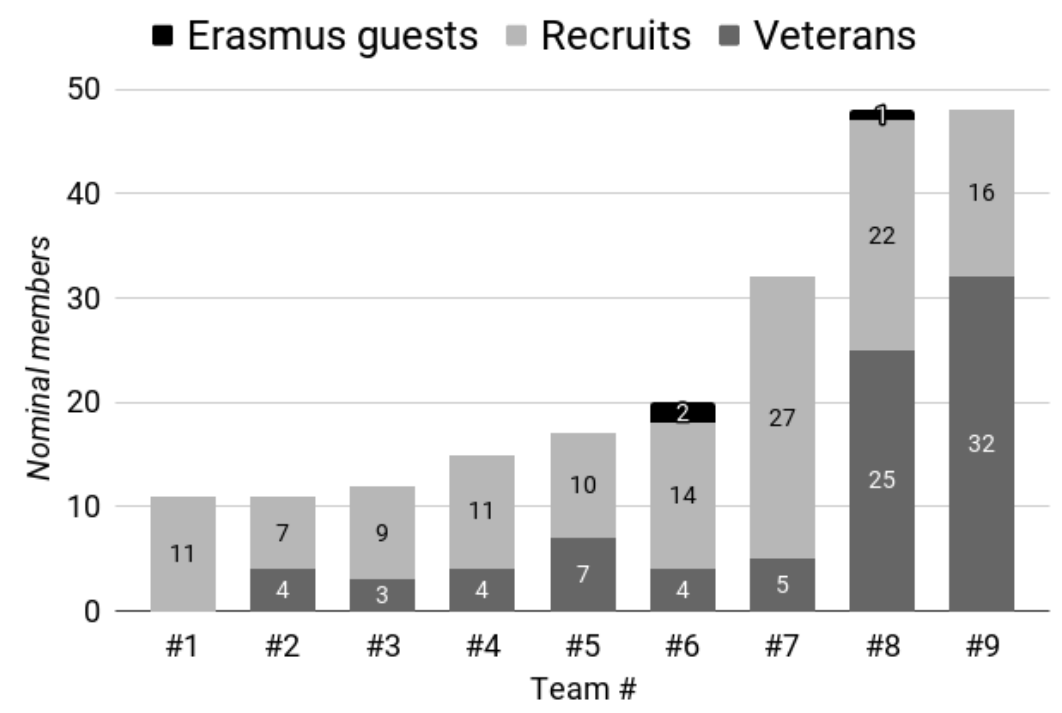

Figure 2. Team members evolution from Team \#1 (2008/09/10) to Team \#9 (2017/18).

- restart: team \#5 focused on the green mobility project and succeeded in making a new vehicle, although the final result was not remarkable from a technical point of view;

- now or never: team \#6 followed exactly this approach when choosing to finalize a speed-bike project to attend the World Human Powered Speed Challenge (WHPSC) yearly organized in Nevada (US) by the IHPVA (International Human Powered Vehicle Association) [22]. That was perceived as a dream target since the beginning of the whole team experience and the team felt that more delay would have been detrimental to the entire project;

- enthusiasm: the visibility gained by the previous team attracted more students and provided strong motivations for team \#7 to improve the existing HPV and to start designing a new one;

- persistence: team \#8 demonstrated to be persistent in working towards high speed HPVs, despite the world record was pushed at a discouraging level in the previous WHPSC edition by a Canadian team [23];

- awareness: by working on important details to evolve the previous project, team \#9 reached a new level of technical knowledge that was rewarded by a great result in the WHPSC, winning the competition and becoming the 4 th fastest in the history of this discipline, at $0.02 \mathrm{~km} / \mathrm{h}$ from the 3rd and $0.52 \mathrm{~km} / \mathrm{h}$ from the $2 \mathrm{nd}$.

This progress, involving an overall number of 130 students through years, was possible thanks to a combination of factors. It is clear from the above described path that in the 1st phase the overall project suffered by the lack of experience (both technical and managerial) and, even more, by the lack of an ambitious goal (such as a world record). However, phase 1 helped the faculty staff to develop managerial skills and to reshape the project up to its current organization. Two key factors surely contributed to make this evolution possible: a significant time investment from the faculty staff, driven by passion for the HPV topic and for the PBL approach in engineering education, and the persistence of the cyclist Andrea Gallo, which is deeply involved since team \#2 (except a temporary suspension during team \#4 and \#5).

In the following section, factors that determined an increase in student attendance and active participation rate in the last three years will be analysed and discussed.

\section{Factors affecting student attendance and active participation}

The attractiveness of an HPV project for engineering students is quite trivial to explain: a sport related topic, with a competition promising unusually high speeds for a bicycle on flat (far over 


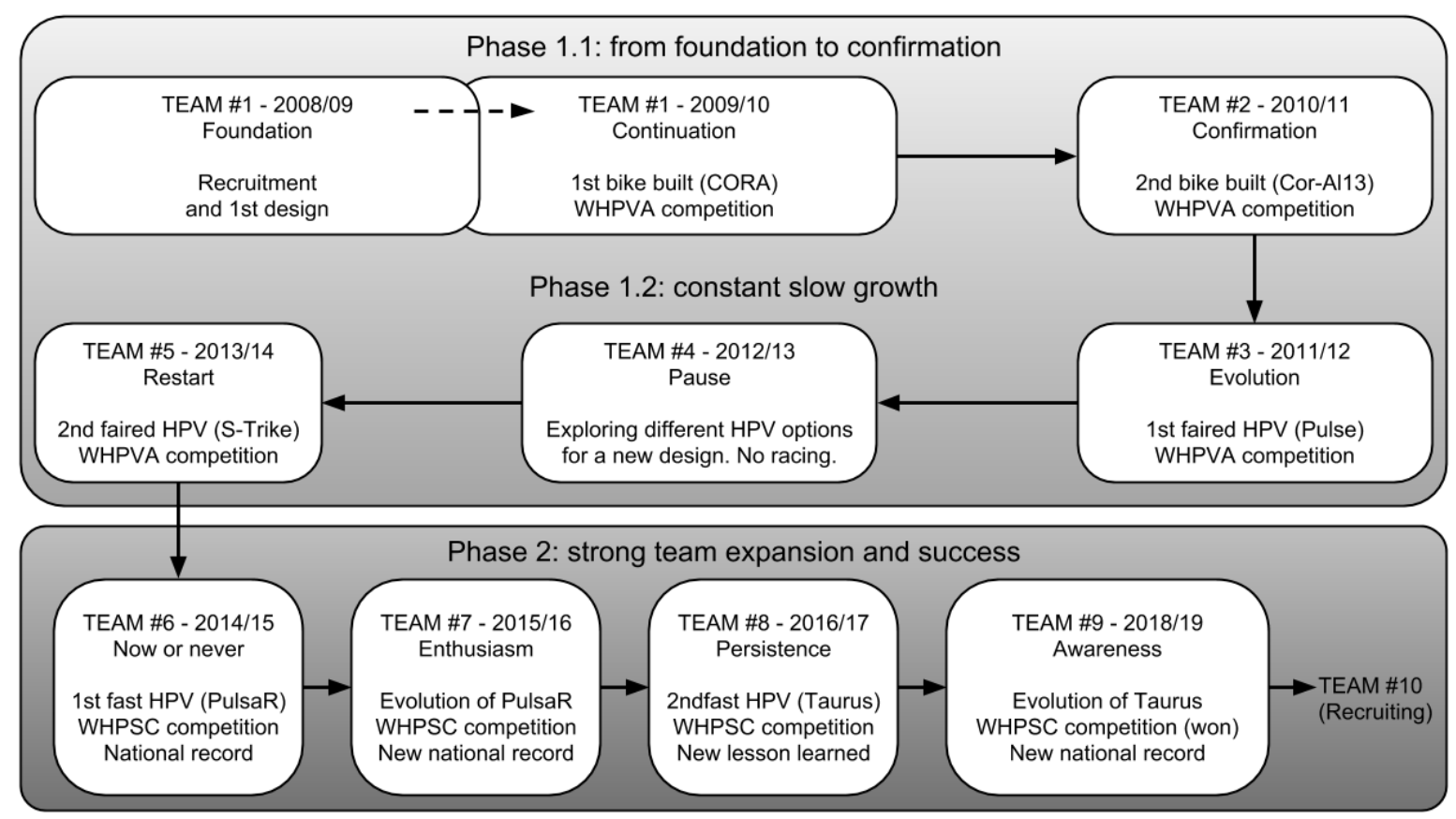

Figure 3. Project evolution from Team \#1 (2008/09/10) to Team \#9 (2017/18).

$100 \mathrm{~km} / \mathrm{h}$ ). What a young hopeful engineer can ask more? From the first overview of the project by means of pictures and videos, the idea of achieving such a speed for a human on his own muscles is able to trigger curiosity and emotional involvement in most of the students.

The attractiveness of "speed" is clearly emerging from the jump in recruitments for team \#7 (Figure 2). The first WHPSC participation in September 2015 (team \#6) had a boosting effect on this ST-PBL attractiveness thanks to an increased local and national media coverage and to the fascination of challenging a world speed record. Indeed, while the recruitment from Team \#1 to \#6 was totally open, with a dozen of candidates per year and without any selection process, starting from team \#7 the recruitment had to face with almost 100 applicants per year. Then, a selection process started to be accurately defined and limited to specific positions within the project. Also, the percentage of veterans opting for a continuation of their experience was increased after the WHPSC participation, in particular from team \#7 to \#8 where $78 \%$ of the previous members opted to prosecute. There is a specific reason for this trend: team \#7 has worked in parallel to the upgrade of a previous prototype (PulsaR) and to the design of a new one (Taurus) for the next year. As a consequence, almost all students that had a role in the new design were strongly motivated to stay and see their idea taking shape. Moreover, the sub-group of team \#7 that went to Nevada in 2016 was so excited by the experience that they wanted definitely see the project improving and it was natural for them to become each one responsible of a team section.

The main braking force for new students to get really involved is the lack of self-awareness about the contribution they can provide to the project. With respect to this, the authors suggest it is important to provide them an overview of the expected (ideal) progression, as in the following example list:

- $\quad$ within 1 month: all recruits will explore previous team vehicles to gain knowledge about technical vocabulary, issues, potential improvements, successful sub-systems to be preserved;

- within 3 months: all recruits will be able to classify design features and related activities by importance and by logical sequence. Then they will define a specific team sub-group to be involved in and a sub-topic to develop their expertise;

- within 6 months: recruits will develop a robust knowledge in their sub-topic and will be able to propose strategies, activities and technical solutions for improvement of the existing or for development of a new vehicle. 
However, such ideal progression is a reference model and, in most cases, the activity is already ongoing when new members are selected. As a consequence, they are specifically addressed to a sub-group since the recruiting assessment and gradually introduced to their tasks with a learning-while-doing approach, which raises the risk for the less skilled recruits to feel inadequate and potentially abandon the project ro to become totally inactive. The previously stated active participation rates during the two phases takes into account for two typical phenomena in Team PBL experiences:

1. some veterans stay in the group because of their emotional connection to the project, but then eventually become inactive since focused on other study deadlines when is time to conclude their educational path;

2. new members approaching the team for the fascination of the challenge, but then becoming inactive since they underestimated the required time investment or think to be unable to contribute or had difficult to integrate within the pre-existing group, etc. Obviously in this case, students abandoning the project do not get any credit.

In general, it is interesting to observe how the percentage of inactive students dropped with the recent member increase starting from Team \#7. This trend is ascribed by the authors to a combination of factors:

- the introduction of a recruitment process based on curricula and a short interview (held by veteran members), allows to identify the most reliable and motivated profiles among candidates;

- a more structured organization (as necessary for a large group) of the whole activity with sub-groups, clear roles, detailed responsibilities for some of the veterans gives to new members a better perception of their role and of the overall framework;

- a "fly-wheel" effect. It has been observed that most of the team members behave as "followers". Within a small group of 10 students, if 2 members are really involved and 3 become inactive, the remaining 5 "followers" tends to loose interest and to become inactive. However, within a large team of 50 students, with a base group of 10-12 strongly motivated members (i.e. 6-7 veterans plus 4-5 well selected recruits), even when 10-15 members become inactive, the remaining "followers" tend to actively participate and this enables a virtuous circle;

- during each year, around March, team members can (optionally) apply for the upcoming trip to the WHPSC in Nevada, which is held in September (overlapping one exam session). The budget usually allows for up to 14-15 participants, including the rider and the technical advisor. Then, a selection is made by the faculty staff, giving priority to the level of active participation, to the "usefulness" of each member and considering a ratio of about 3:7 between veterans and recruits.

The last point may look critical in the overall management since an "evaluation" in the middle of such an yearly project could potentially change the group equilibrium. However, the authors were positively surprised, up to now, by the student reaction to that. Firstly, the optionality of such application implies a self-assessment of the students and, with few exceptions, members that were inactive during the first semester usually abstained from applying. Then, although the authors expected a raise in participation for the selected sub-group and, eventually, some defection among the non-selected, this did not happened in general. Beside very few exceptions, an increased participation was noticed also for the non-selected students, that probably became aware of their under-average contribution until that moment. In any case, after the selection, a detailed follow-up explaining all the factors that ruled the choice is always made and eventually discussed with the entire group.

\section{Learning transportation sustainability through HPV design}

Moving from PBL general management to the specific topic of the project, some considerations can be made with respect to the impact it has on the participant educational path.

Apart few exceptions, students approaching the team are quite unaware of what an HPV is. They are familiar with the bicycle in its most popular forms: road racing, commuting, mountain bikes and 
few other categories. Obviously, being involved in such specific PBL, most of them will acquire a wider perception of HPV technologies and market, however this is not the most interesting learning outcome.

\subsection{The relativity of "perfection"}

The most popular design and shape of a vehicle (i.e. the safety bicycle among HPVs) could not represent the absolute optimal with respect to all specific requirements. Many cycling enthusiasts often refer to the safety bicycle as "the perfect machine". However, this definition can be wrong depending on the premises: perfect for what? Not for comfort and ergonomics since the recumbent position is more naturally accepted by our body and prevents many typical cycling pathologies. Not for speed and efficiency on flat and smooth roads, as other HPVs can reach much higher speeds for the same amount of power input in these conditions. Maybe for climbing roads with high slope, although not proven by any scientific comparison. Maybe as a practical vehicle for everyday commuting, although it has a conflicting cohabitation with motorized vehicles in many contexts.

Also, it happens to hear that "bicycle design naturally evolved toward the optimal solution", ignoring that such technical evolution has been strongly driven by boundary conditions imposed by UCI rules, a sport federation. Those rules not only affected the evolution of road racing bicycles, but, by conditioning the popular perception of what a bicycle is, they defined the technical solution for all other kind of bicycles, including those intended for everyday commuting.

Students entering an HPV Team will gain awareness of these concepts and will be more cautious with respect to popular sentences about "perfection" of a machine, technical evolution towards optimal solutions or other similar misconception.

\subsection{The project as a compromise}

The already mentioned need for a compromise in every project, even for the most specialized machine such as a world record aiming HPV: aerodynamics, rolling resistance and transmission efficiency are the design leading features. However, the rider has to fit inside the shell, to reach the pedals with physiological knee angles and to have a good perception of safety to deliver all his power. In addition, the steering must be sufficient for the assisted start and stop, the vehicle weight is not to be neglected, the shell needs a split for the entrance and a safe locking system operable from the external in case of crash, and so on. All these additional aspects challenge the group to find a compromise with respect to the three initial leading features.

\subsection{The importance of data-driven decisions}

In HPV competitions, the rider feedback plays an important role to fix and tune the vehicle, but it can be sometime misleading due to its subjective nature. During the year of activity, the students learn to process and analyse the rider feedbacks with a critical approach by taking into account specific boundary conditions. As an example, if the rider feels new tires are "rolling better", the information is stored as "opinion" and critically analysed when back from testing: was really the tire or the smoother road? Or the lighter bike? Or the better wheel rim where the tire is mounted on? More objective lab or road measurements are then considered and planned in order to collect data before considering such tires "faster".

\subsection{A human-centred perspective on power, energy consumption and emission concepts}

With the end goal to teach future engineers for a greener way to deal with transportation, we have to ensure that they truly comprehend the meaning of physical quantities and develop a practical perception about their order of magnitude. Power and energy amounts tends to lose their human-focused reference point when they are exclusively taught from a motorized point of view. Although young engineers are able to understand and define power and energy for a variety of motorized vehicles, they are often unable to relate them to what a human can do on his own muscles, 
which is the most basic, direct and practical experience we can have, as humans, about these quantities. If the next generation of engineer and technicians is asked to develop more sustainable transportation systems, it is desirable for them to have a clear human-centred perception of power and energy.

Focusing in detail on the WHPSC, scope of the competition is to reach the highest speed in a timed portion of $200 \mathrm{~m}$ at the end of a $8 \mathrm{~km}$ run-up on a straight and smooth asphalt road. The road has a negative slope of $0.6 \%$, that gives a not negligible contribution. Resistive forces are typical of many land vehicles: aerodynamic drag, $F_{d}$, and tire rolling resistance, $F_{r}$, with their classical formulations:

$$
F_{d}=\frac{1}{2} \cdot \rho \cdot C_{d} \cdot A \cdot v^{2}
$$

and

$$
F_{r}=m \cdot g \cdot C_{r r}
$$

where $\rho$ is the fluid (air) density, $C_{d}$ is the drag coefficient assessing the goodness of an object shape, $A$ is a reference area for the object (usually the projected area in the flow direction when pressure is the dominant resistance), $v$ is the relative speed of the object into the fluid, $m$ is the overall mass, $g$ is the gravitational constant and $C_{r r}$ is the so called rolling resistance coefficient. Moreover, both $C_{d}$ and $C_{r r}$ are speed dependent in the considered range of speed $(0-145 \mathrm{~km} / \mathrm{h})$ [24]. Finally, the transmission system from the pedal to the wheel (usually involving chain and sprockets) provides additional losses to be minimized.

Another important analysis that students are required to make in order to fully understand the challenge is about the mass. This parameter is well known for playing an important role in traditional road cycling, where climbing on significant slopes is a dominant condition. At a first approach, given almost flat road of the WHPSC, the overall mass (vehicle plus rider) may appear as a negligible parameter. However, students will learn that the balance is more complicated:

- the mass of an athlete is proportional to his power output and male cyclists can deliver a power to weight ratio between $5 \mathrm{~W} / \mathrm{kg}$ (elite) and $6 \mathrm{~W} / \mathrm{kg}$ (professional) for an exercise of about $300 \mathrm{~s}$ [25] as the WHPSC is;

- the rider mass, however, affects his size and thus the vehicle frontal area and wet surface, directly influencing the aerodynamic as shown in Eq. 1;

- given the small but not negligible descending slope of the road used at the WHPSC, higher overall mass means more gravity potential energy available at the start;

- the overall mass directly affects the power dissipated by tire rolling resistance as shown in Eq. 2;

- given the limited length of the run, a significant amount of energy has to be spent in acceleration, so that the overall mass and the mass of rotating parts play a role by directly contributing to inertial forces.

The last point is usually considered as a secondary aspect at a first glance. However, the more a team get closer to the top competitor speeds, the more its importance become clear. An example calculation is usually proposed to the students in order to clarify the concept: accelerating from $120 \mathrm{~km} / \mathrm{h}$ to $140 \mathrm{~km} / \mathrm{h}$ in $4 \mathrm{~km}$ (half the run-up), with an overall mass of $100 \mathrm{~kg}$, an average power of $181 \mathrm{~W}$ is required to overcome the inertial forces. That amount is to be summed up with the power dissipated by resistive forces in such range of speed. Moreover, that hypothetical scenario requires the rider to accelerate from $0 \mathrm{~km} / \mathrm{h}$ to $120 \mathrm{~km} / \mathrm{h}$ in the first $4 \mathrm{~km}$. With a similar approach the entire course can be split into a growing number of sub-sections for a more accurate evaluation. It can be easily demonstrated that each percentage of mass reduction will provide an equivalent saving percent in terms of "inertial power" for acceleration. The usual conclusion of the recruited students is that an infinite length run-up would solve the question by minimizing the role of acceleration, however this would lead to a prolonged exercise, that means a reduced amount of power to weight ratio available from the rider [25], shifting the challenge to a different perspective. 


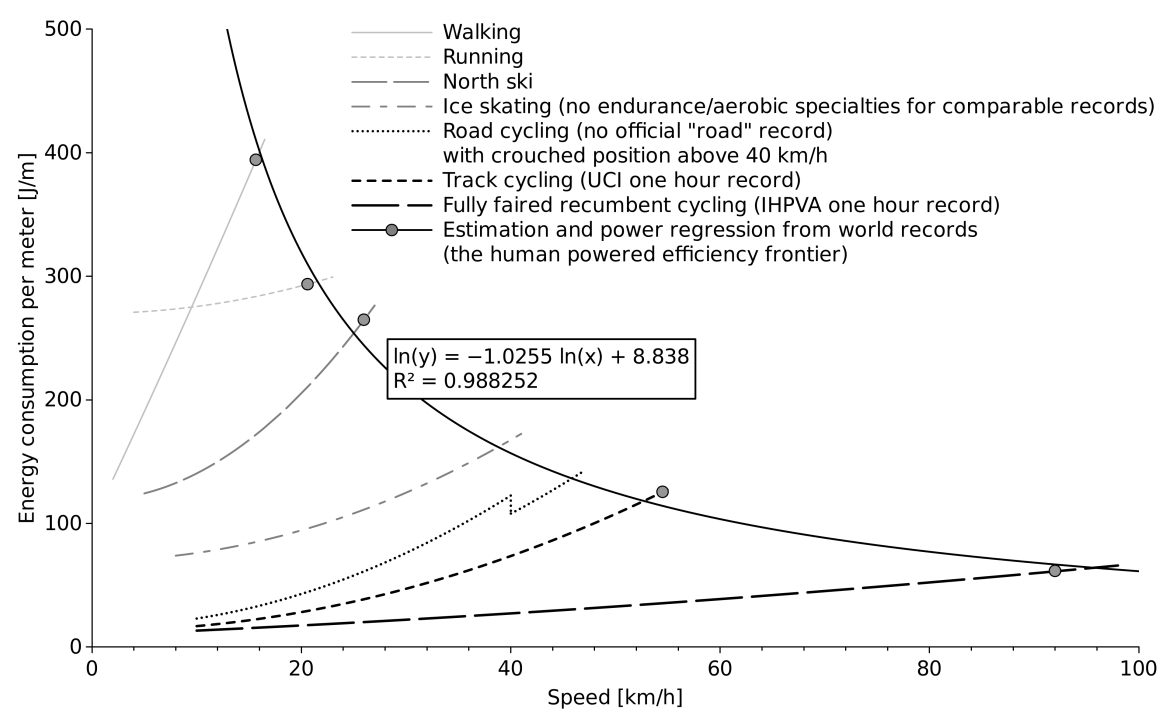

Figure 4. Energy consumption per meter as a function of speed for different human powered modes in steady aerobic conditions.

Finally, by comparing these extreme competition vehicles with other human powered activities and with motorized transportation means, the future engineer will have a wider vision and a more comprehensive perspective about two fundamental concepts: energy consumption (the reciprocal of transportation efficiency) and $\mathrm{CO}_{2}$ emission. Two comparison plots (Figures 4 and 5), derived from literature data [25-27], are proposed to the students during the project. Even if not strictly related to their speed record goal, they usually raise great curiosity and occasionally the topic has been developed more in depth by some of them.

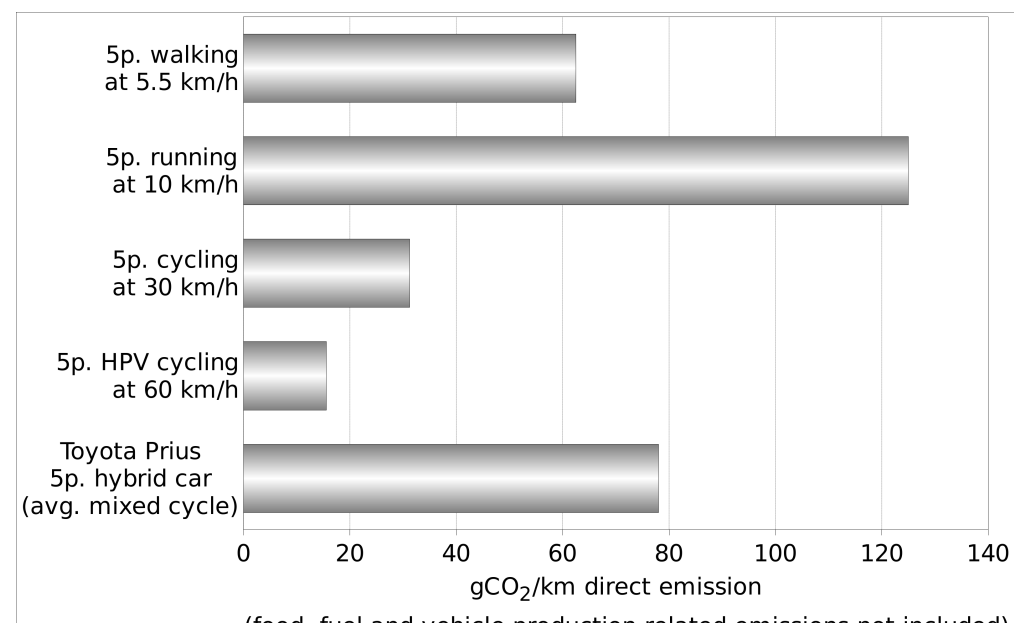

Figure 5. $\mathrm{CO}_{2}$ emission per $\mathrm{km}$ for 5 people in human powered activities and in a modern hybrid car.

\section{Conclusions}

A decennial experience of a student team focused on HPV design within a PBL activity at Politecnico di Torino was presented in this article. The PBL evolution and growth has been analysed by identifying boundary conditions and key factors that determined the project path through years and the student attendance and active participation. As typical in every successful project, it emerges that good results are just the tip of an iceberg underlying a remarkable time investment, trial and errors and persistence. Finally, the value and the learning outcomes that such kind of experience provides to 
engineering students have been discussed, with particular reference to the HPV design topic and in relation to transportation sustainability.

Funding: The Policumbent Team PBL activity was funded by the Commission for Contributions and Student Projects of Politecnico di Torino.

Conflicts of Interest: The authors declare no conflict of interest.

\section{Abbreviations}

The following abbreviations are used in this manuscript:

HPV Human Powered Vehicle

IHPVA International Human Powered Vehicle Association

PBL Project Based Learning

ST-PBL Student Team Project Based Learning

UCI Unione Cycliste Internationale

WHPVA World Human Powered Vehicle Association

WHPSC World Human Powered Speed Challenge

1. Krajcik, J.S.; Blumenfeld, P.C., Project-Based Learning. In The Cambridge Handbook of the Learning Sciences; Sawyer, R.K., Ed.; Cambridge Handbooks in Psychology, Cambridge University Press, 2005; p. 317-334. doi:10.1017/CBO9780511816833.020.

2. Gülbahar, Y.; Tinmaz, H. Implementing project-based learning and E-portfolio assessment in an undergraduate course. Journal of Research on Technology in Education 2006, 38, 309-327. doi:10.1080/15391523.2006.10782462.

3. Perrenet, J.C.; Bouhuijs, P.A.J.; Smits, J.G.M.M. The Suitability of Problem-based Learning for Engineering Education: Theory and practice. Teaching in Higher Education 2000, 5, 345-358. doi:10.1080/713699144.

4. KOLMOS, A. Reflections on Project Work and Problem-based Learning. European Journal of Engineering Education 1996, 21, 141-148. doi:10.1080/03043799608923397.

5. Blumenfeld, P.C.; Soloway, E.; Marx, R.W.; Krajcik, J.S.; Guzdial, M.; Palincsar, A. Motivating Project-Based Learning: Sustaining the Doing, Supporting the Learning. Educational Psychologist 1991, 26, 369-398, [arXiv:1011.1669v3]. doi:10.1080/00461520.1991.9653139.

6. Lehmann, M.; Christensen, P.; Du, X.; Thrane, M. Problem-oriented and project-based learning (POPBL) as an innovative learning strategy for sustainable development in engineering education. European Journal of Engineering Education 2008, 33, 283-295. doi:10.1080/03043790802088566.

7. Bell, S. Project-Based Learning for the 21st Century: Skills for the Future. The Clearing House: A Journal of Educational Strategies, Issues and Ideas 2010, 83, 39-43. doi:10.1080/00098650903505415.

8. Helle, L.; Tynjälä, P.; Olkinuora, E. Project-based learning in post-secondary education - Theory, practice and rubber sling shots. Higher Education 2006, 51, 287-314, [arXiv:1002.2562v1]. doi:10.1007/s10734-004-6386-5.

9. Markham, T. Project based learning: a bridge just far enough. Teacher Librarian 2011, 39, 38.

10. DeFillippi, R.J. Introduction: Project-based Learning, Reflective Practices and Learning Outcomes. Management Learning 2001, 32, 5-10, [arXiv:0803973233]. doi:10.1177/1350507601321001.

11. Ifenthaler, D.; Siddique, Z.; Mistree, F. Exploring learning how to learn in a team-based engineering education. Interactive Technology and Smart Education 2014, 11, 63-82. doi:10.1108/ITSE-10-2013-0025.

12. Knight, D.W.; Carlson, L.E.; Sullivan, J.F. Improving Engineering Student Retention through Hands-On, Team Based, First-Year Design Projects. 31st International Conference on Research in Engineering Education 2007, p. 13.

13. Denton, H. Multidisciplinary team-based project work: planning factors. Design Studies 1997, 18, $155-170$. doi:10.1016/S0142-694X(97)85458-0.

14. Borrego, M.; Karlin, J.; Mcnair, L.D.; Beddoes, K. Team effectiveness theory from industrial and organizational psychology applied to engineering student project teams: A research review. Journal of Engineering Education 2013, 102, 472-512. doi:10.1002/jee.20023. 
15. Weloa, T.; Tonninga, O.R.B.; Rølvåga, T. Lean Systems Engineering (LSE): Hands-on experiences in applying LSE to a student eco-car build project. Procedia Computer Science, 2013, Vol. 16, pp. 492-501. doi:10.1016/j.procs.2013.01.052.

16. Jensen, D.; Wood, J.; Wood, K. Hands-on activities, interactive multimedia and improved team dynamics for enhancing mechanical engineering curricula. International Journal of Engineering Education 2003, 19, 874-884.

17. Moylan, W.A. Learning by project: developing essential 21st century skills using student team projects. International Journal of Learning 2008, 15, 287-292. doi:10.1016/j.radphyschem.2014.11.017.

18. Seidel, R.; Godfrey, E. Project and Team based Learning: An Integrated Approach to Engineering Education. Proceedings of the 2005 ASEE/AaeE 4th Global Colloquium on Engineering Education, 2005, pp. 1-9.

19. Student Teams and Projects at Politecnico di Torino, 2018. https://didattica.polito.it/team_studenteschi.html, accessed on 2018-10-19.

20. Policumbent, 2018. http://www.policumbent.it, accessed on 2018-10-19.

21. WHPVA, 2018. http:/ / www.whpva.org, accessed on 2018-10-19.

22. IHPVA, 2018. http://www.ihpva.org, accessed on 2018-10-19.

23. Aerovelo, 2016. http://www.aerovelo.com, accessed on 2018-10-19.

24. Baldissera, P. Proposal of a coast-down model including speed-dependent coefficients for the retarding forces. Proceedings of the Institution of Mechanical Engineers, Part P: Journal of Sports Engineering and Technology 2017, 231, 154-163. doi:10.1177/1754337116658587.

25. Wilson, D.G. Bicycling Science, 3rd edition, 3rd editio ed.; MIT Press, 2004; p. 471.

26. Minetti, A.; Pavei, G.; others. CO2 emission of locomotion: innovative automobiles do better than running humans. Physiology News 2011, 83, 24-26.

27. Di Prampero, P.E. The energy cost of human locomotion on land and in water, 1986. doi:10.1055/s-2008-1025736. 